\title{
LA PROPIEDAD PRIVADA Y SU FUNCIÓN SOCIAL A LA LUZ DE CIEN AÑOS DE ENCÍCLICAS (DE LA RERUM NOVARUM A LA CENTESIMUS ANNUS)
}

\author{
Vidal Rivera Sabatés \\ Departamento de Derecho Civil \\ Facultad de Derecho \\ Universidad Complutense de Madrid \\ vrivera@der.ucm
}

\section{RERUM NOVARUM}

El lúcido y providentísimo ${ }^{1}$ pontífice León XIII publicó, ya en su sabia ancianidad $^{2}$ (el 15 de mayo de 1891), la monumental encíclica Rerum Novarum $^{3}$, carta magna del orden social. En ella, frente a las tesis socialistas que propugnaban la necesidad de acabar con la propiedad privada y consideraban conveniente que todas las cosas fueran comunes y administradas por las personas que regían el municipio o gobernaban la nación ${ }^{4}$, el obispo de Roma sentencia que el «poseer algo en privado como propio es un derecho dado al hombre por la naturaleza» ${ }^{5}$. Dicho hombre, único animal pro-

${ }^{1}$ Así lo califica otro papa, Pío XI, en el núm. 29 de la encíclica Quadragesimo Anno, publicada el 15 de mayo de 1931, disponible en bttp://w2.vatican.va/content/pius-xi/es/ encyclicals/documents/hf_p-xi_enc_19310515_quadragesimo-anno.btml.

2 León XIII (Vincenzo Gioacchino Pecci), el «Papa de los Obreros», había nacido en Carpineto (Anagni) el 2 de marzo de 1810.

${ }^{3}$ Http://w2.vatican.va/content/leo-xiii/es/encyclicals/documents/bf_I-xiii_enc_1505189 1_rerum-novarum.pdf.

${ }^{4}$ Cfr. Rerum Novarum, núm. 3.

5 Ibid., núms. 4, 7, 17 o 33. En nuestro Código Civil, el art. 430 establece que «posesión civil es la tenencia de una cosa o el disfrute de un derecho por una persona. Posesión civil es esa misma tenencia o disfrute unidos a la intención de haber la cosa o derecho como suyos». $\mathrm{El}$ art. 432 de idéntico texto concreta que «la posesión en los bienes y derechos puede tenerse en uno de dos conceptos: o en el de dueño o en el de tenedor de la cosa o derecho para conservarlos o disfrutarlos, perteneciendo el dominio a otra persona». Una duda tradicional entre los civilistas es si este segundo precepto contiene la misma distinción que la residenciada en el primero de ellos. Probablemente, colige M. YzQuiERDo Tolsada, Lecciones sobre pose- 
visto de razón, ha de tener no sólo el uso de los bienes (cual si se tratase de una fiera), sino también la posibilidad de poseerlos «con derecho estable y permanente» ${ }^{6}$, sean tales bienes consumibles o inconsumibles ${ }^{7}$.

Según argumenta el papa, la circunstancia de que «Dios haya dado la tierra para usufructuarla y disfrutarla a la totalidad del género humano no puede oponerse en modo alguno a la propiedad privada» ${ }^{8}$. Y cuando proporcionó esta tierra globalmente a la humanidad no lo hizo «porque quisiera que su posesión fuera indivisa para todos, sino porque no asignó a nadie la parte que habría de poseer, dejando la delimitación de las posesiones privadas a la industria de los individuos y a las instituciones de los pueblos»? Eso sí, aunque la tierra se encuentre distribuida entre los particulares, no se olvida, sin embargo, de «servir a la común utilidad de todos» ${ }^{10}$, toda vez que no existe ningún mortal que no se alimente con lo que las fincas producen. Quienes carecen de propiedad suplen tal carencia con el trabajo; de manera que es menester concluir que «el medio universal de procurarse la comida y el vestido está en el trabajo, el cual, rendido en el fundo propio o en un oficio mecánico, recibe, finalmente, como merced no otra cosa que los múltiples frutos de la tierra o algo que se cambia por ellos» ${ }^{11}$.

Si un obrero cabal, disminuyendo sus gastos, logra ahorrar unas monedas y las invierte en un predio, con lo que puede asegurarse más su manutención, ese terreno viene a representar «el mismo salario revestido de otra apariencia, y de ahí que la finca adquirida por el obrero de esta forma debe ser tan de su dominio como el salario ganado» ${ }^{12}$ con su labor.

La práctica de los siglos ha consagrado a la propiedad privada (o dominio) ${ }^{13}$, merece la pena insistir en ello, como una figura muy acorde

sión y usucapión (con anexos jurisprudenciales), Madrid, Dykinson, 2002, p. 16, sea todo un problema terminológico en el que la única vía de «salvar la aparente reiteración consiste en entender que la posesión en concepto de dueño es uno de los ingredientes de la posesión civil: ésta necesita ser en concepto de dueño, pero también ser pública, pacífica e ininterrumpida».

${ }^{6}$ Rerum Novarum, núm. 4.

7 Es decir, aquellos que, pese al uso que se hace de ellos, perduran. Cfr. Rerum Novarum, núm. 4. Vid. también el art. 337 CC.

${ }^{8}$ Rerum Novarum, núm. 6.

${ }^{9}$ Ibid.

${ }^{10}$ Ibid. Vid. también F. Rodríguez, «Tres versiones de la encíclica Rerum Novarum», Revista de Política Social, núm. 10 (1951), p. 73.

${ }^{11}$ Rerum Novarum, núm. 6.

${ }_{12}$ Ibid., núm. 3.

13 «Sin escrúpulos técnicos pueden emplearse como sinónimos [los términos] propiedad y dominio». Vid. G. Cabanellas, voz «propiedad», Diccionario de derecho usual, t. III, 7. a ed., Buenos Aires, Heliasta, 1972, p. 407. Vid., asimismo, F. García Goyena, Concordancias, motivos y comentarios del Código Civil español, t. I, arts. 391 y 392, Madrid, Impren- 
con la naturaleza del hombre y «la más conforme con la pacífica y tranquila convivencia» ${ }^{14}$. Las leyes civiles, que, si son justas, extraen su vigor de semejante ley natural, confirman y protegen incluso con la fuerza ese pleno derecho real ${ }^{15}$, transmisible por herencia a los hijos ${ }^{16}$. El Estado tiene que preservar la inviolabilidad del dominio ${ }^{17}$ y favorecer que la mayoría de los integrantes «de la masa obrera tenga algo en propiedad» ${ }^{18}$, lo que, entre otras innegables ventajas, generaría una más equitativa distribución de las riquezas ${ }^{19}$. La apelación a un difuso bien común no autoriza «quitar a otro lo que es suyo o, bajo capa de una pretendida igualdad, caer sobre las fortunas ajenas» ${ }^{20}$ : hay que evitar el eventual peligro de rapiñas para los legítimos dueños ${ }^{21}$. No obstante, le cabe al poder público, llegado el caso, moderar el uso de las cosas por sus dueños y compaginar esa utilización con el bienestar o provecho de la colectividad ${ }^{22}$.

Resulta lícito, por tanto — subrayaba Santo Tomás de Aquino-, que el hombre posea cosas propias, y además se torna imprescindible para la vida humana por tres motivos: «primero, porque cada uno es más solícito en gestionar aquello que con exclusividad le pertenece que lo que es común a todos o a muchos, puesto que cada cual, huyendo del trabajo, deja a otros el cuidado de lo que conviene al bien común, como sucede cuando hay

ta de la Sociedad Tipográfico-Editorial, 1852, pp. 352-353, y J. L. LACRUZ Berdejo, Elementos de Derecho civil, III, vol. I, 3. ${ }^{a}$ ed. revisada y puesta al día por A. Luna SERRAno, Madrid,

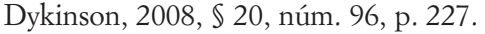

14 Rerum Novarum, núm. 8.

15 Haciendo de él un derecho seguro. Cfr. la encíclica — también de León XIII de 10 de febrero de 1880-Arcanum Divinae Sapientae, núm. 2, disponible en bttp://w2.vatican.val content/leo-xiii/es/encyclicals/documents/hf_l-xiii_enc_10021880_arcanum.pdf.

${ }^{16}$ Rerum Novarum, núm. 9. Vid. al respecto, también, el art. 33.1 CE.

17 Rerum Novarum, núms. 11 y 33. Cfr., asimismo, la STC de 19 de diciembre de 1986, FJ 13 (RTC 1986/166).

${ }_{18}$ Rerum Novarum, núm. 33. Vid. también los núms. 26 y 34 del Radiomensaje de Navidad de Su Santidad Pío XII, de 24 de diciembre de 1942, disponible en bttps://w2.vatican.va/content/pius-xii/es/speeches/1942/documents/hf_p-xii_spe_19421224_radiomessage-christmas.pdf.

${ }_{19}$ Rerum Novarum, núm. 33. Vid., asimismo, el núm. 12 del Radiomensaje de Su Santidad Pío XII en el quincuagésimo aniversario de la Rerum Novarum (La solennità), de 1 de junio de 1941, disponible en https://w2.vatican.va/content/pius-xii/es/speeches/1941/documents/hf_p-xii_spe_19410601_radiomessage-pentecost.pdf, o el núm. 34 de la encíclica Sertum Laetitiae del mismo Pío XII con motivo del ciento cincuenta aniversario de la institución de la jerarquía en Estados Unidos, de 1 de noviembre de 1939, disponible en bttp://w2.vatican.val content/pius-xii/en/encyclicals/documents/bf_p-xii_enc_01111939_sertum-laetitiae.btml.

${ }^{20}$ Rerum Novarum, núm. 28.

${ }^{21}$ Evitando, por ejemplo, la dureza de los tributos e impuestos. Ibid., núm. 33.

${ }^{22}$ Ibid., núm. 33. Vid. igualmente V. Montés Penadés, Comentario del Código Civil, dirigido por C. Paz-Ares Rodríguez, R. Bercovitz, L. Díez-Picazo Ponce de León y P. SalVADOr CODERCH, t. I, art. 348, Madrid, Ministerio de Justicia, 1991, p. 957. 
multitud de servidores; segundo, porque se administran más ordenadamente las cosas humanas si a cada uno le incumbe el cuidado de sus propios intereses; sin embargo, reinaría confusión si cada cual se cuidara de todo indistintamente; tercero, porque así el estado de paz entre los hombres se mantiene si cada uno está contento con lo suyo. De ahí que veamos que entre aquellos que en común y pro indiviso poseen alguna cosa se suscitan más frecuentemente contiendas» ${ }^{23}$. ¡A fe que sí! La comunidad engendra por desgracia, más pronto que tarde, disensiones entre sus miembros (tal como reza el aforismo de la jurisprudencia romana, «communio mater est discordiarum») ${ }^{24}$.

La propiedad privada se halla también amparada —agregará León XIII— por lo demás, amén de por las leyes humanas, por los preceptos divinos, que prohíben hasta el simple deseo de lo ajeno: «No desearás la mujer de tu prójimo, ni la casa, ni el campo, ni la esclava, ni el buey, ni el asno, ni nada de lo que es suyo (Dt. 5, 21)» ${ }^{25}$.

\section{QUADRAGESIMO ANNO}

Cuatro décadas después de que viera la luz la egregia ${ }^{26}$ e inmortal ${ }^{27}$ Rerum Novarum, al objeto de conmemorar con solemne gratitud tan señalada fecha ${ }^{28}$, el papa Pío XI publicó el 15 de mayo de 1931 la encíclica Quadragesimo Anno, que versa, como ella misma indica, sobre la restauración del orden social en perfecta conformidad con la ley evangélica.

En este último texto Pío XI, suscribiendo las ideas de su ensalzado predecesor en la cátedra de San Pedro, estima que la supresión de la propiedad privada, «lejos de redundar en beneficio de la clase trabajadora ${ }^{29}$,

${ }^{23}$ Santo Tomás DE Aquino, Suma Teológica, parte II-IIae, cuestión 66, art. 2, disponible en http://hjg.com.ar/sumat/index.html.

${ }^{24}$ Cfr. el considerando primero de la STS de 28 de noviembre de 1957 (RJ 1957/3424); el fundamento de Derecho 1. ${ }^{\circ}$ de las SSTS de 4 de abril de 1997 (RJ 1997/2637), 7 de julio de 2006 (RJ 2006/7219), 27 de marzo de 2009 (RJ 2009/2392) y 15 de diciembre de 2009 (RJ 2010/287), o el fundamento de Derecho 9. ${ }^{\circ}, 1$, de la STS de 3 de marzo de 2016 (RJ 2016/947).

${ }^{25}$ Cfr. Rerum Novarum, núm. 8.

${ }^{26}$ Cfr. Quadragesimo Anno, núm. 1. Vid. nota 1.

${ }^{27}$ Ibid., núms. 39 o 147. En el núm. 22 de la misma encíclica se califica al documento leoniano como «memorable».

${ }^{28}$ Y lo hace cumpliendo fielmente el consejo de San Ambrosio de Milán, según el cual no hay «ningún deber mayor que el agradecimiento». Cfr. Quadragesimo Anno, núm. 16.

${ }^{29} \mathrm{Ibid}$., núm. 44. 
constituiría la más completa ruina de los proletarios y «la más atroz de las injusticias» ${ }^{30}$. Ahora bien, dicho planteamiento no significa que haya de ponerse en tela de juicio — destaca el papa lombardo- ${ }^{31}$ el doble carácter de tal derecho de propiedad: a saber, la índole individual y la social, «según se refiera a los individuos o mire al bien común» ${ }^{32}$. La Iglesia siempre ha sostenido, con unanimidad, que «por la naturaleza o por el Creador mismo se ha conferido al hombre el derecho de dominio privado, tanto para que los individuos puedan atender a sus necesidades propias y a las de su familia, cuanto para que, a través de esta institución, los medios que el Creador destinó a toda la familia humana sirvan efectivamente para tal fin, todo lo cual no puede obtenerse, en modo alguno, a no ser observando un orden firme y determinado» ${ }^{33}$. Cuando se descarta de plano el componente social y público del derecho de propiedad se corre el riesgo de caer en un feroz «individualismo», mientras que si se rechaza o reduce el carácter privado (o individual) de ese derecho se desemboca inexorablemente en el «colectivismo» ${ }^{34}$.

El Estado, al armonizar la propiedad privada con las exigencias del bien común, no daña a «los poseedores particulares, sino que, por el contrario, les presta un eficaz apoyo» ${ }^{35}$, en la medida en que impide que la posesión privada de las cosas, que «el Autor de la Naturaleza dispuso para sustento de la vida humana» ${ }^{36}$, provoque menoscabos intolerables o aboque a la ruina propia o ajena: no destruye la propiedad privada, pues la defiende; no debilita el dominio particular, porque lo dota de robustez ${ }^{37}$.

La convivencia social marca unos límites al dominio privado y sujeta al dominus al cumplimiento de ciertos deberes ${ }^{38}$, pero no es dable empe-

\footnotetext{
30 Ibid.

31 Pío XI (Ambrogio Damiano Achille Ratti) nació el 31 de mayo de 1857 en Desio, muy cerca de Milán.

32 Quadragesimo Anno, núm. 45. Vid. también el núm. 35 de su carta encíclica Mit brennender Sorge, de 14 de marzo de 1937, disponible en bttp://w2.vatican.va/content/pius-xi/es/ encyclicals/documents/hf_p-xi_enc_14031937_mit-brennender-sorge.pdf.

${ }_{33}$ Quadragesimo Anno, núm. 45. Vid., asimismo, la carta apostólica Mulieris Dignitatem, núm. 6, dada por San Juan Pablo II el 15 de agosto de 1988, disponible en bttp:// w2.vatican.va/content/john-paul-ii/es/apost_letters/1988/documents/hf_jp-ii_apl_19880815_ mulieris-dignitatem.pdf.

${ }_{34}$ Quadragesimo Anno, núm. 46. Vid. también P. Trimarchi, Istituzioni di Diritto Privato, 11. ${ }^{a}$ ed., Milano, Giuffrè, 1996, p. 530.

${ }_{35}$ Quadragesimo Anno, núm. 49.

36 Ibid.

37 Ibid.

38 Ibid., núm. 47. Cfr. también, en lo relativo a ello, M. Albaladejo García, Derecho Civil

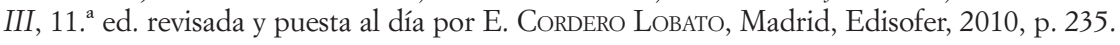


queñecer tanto el contenido de ese derecho subjetivo privado (o restringir hasta tal extremo el ejercicio del mismo) que llegue a anularse o disolverse su concepto ${ }^{39}$. Hoy diríamos que no se consiente tocar el «contenido esencial (o mínimo)» del derecho de propiedad, entendido como «recognoscibilidad de cada tipo de derecho dominical en el momento histórico de que se trate y como practicabilidad o posibilidad efectiva de realización del derecho, sin que las limitaciones y deberes que se impongan al propietario deban ir más allá de lo razonable» (STC de 26 de marzo de 1987, fundamento jurídico $\left.2 .^{\circ}\right)^{40}$. Y se habla aquí, atinadamente, del momento histórico porque, igual que los restantes elementos de la vida social, el dominio no goza de inmutabilidad ${ }^{41}$. Meditando sobre este asunto, Pío XI, citando unas palabras que él mismo había pronunciado en el discurso al Comité de Acción Católica de Italia el 16 de mayo de 1926, exclamará: «Cuán diversas formas ha revestido la propiedad desde aquella primitiva de los pueblos rudos y salvajes, que aún nos es dado contemplar en nuestros días en algunos países, hasta la forma de posesión de la era patriarcal, y luego en las diversas formas tiránicas (y usamos este término en su sentido clásico), así como bajo los regímenes feudales y monárquicos hasta los tiempos modernos» ${ }^{42}$.

Pío XI nos recuerda que «la justicia llamada conmutativa manda, es verdad, respetar santamente la división de la propiedad y no invadir el derecho ajeno excediendo los límites del propio dominio» ${ }^{43}$. Empero, la pertinencia de que un propietario solo haga uso de lo que le pertenece de modo honesto no tiene que ver con la justicia, sino con otras virtudes, como la caridad cristiana $^{44}$ (esto es, el amor fraterno, motor de todo progreso social) ${ }^{45}$, que

39 Quadragesimo Anno, núm. 48.

40 (RTC 1987/37). Vid., asimismo, la STC de 8 de abril de 1981, fundamento jurídico $8 .{ }^{\circ}$ (RTC 1981/11), o la STS de 20 de diciembre de 2005, fundamento jurídico 2. ${ }^{\circ}$ (RJ 2006/288).

${ }^{41}$ Quadragesimo Anno, núm. 49.

42 Ibid.

${ }^{43}$ Ibid., núm. 47.

${ }^{44}$ Practicada ejemplarmente —escribe Benedicto XVI— por Martin de Tours (†397), «que primero fue soldado y después monje y obispo [...] A las puertas de Amiens compartió su manto con un pobre; durante la noche, Jesús mismo se le apareció en sueños revestido de aquel manto». Cfr. la carta encíclica Deus caritas est, núm. 40, de 25 de diciembre de 2005, disponible en http://w2.vatican.va/content/benedict-xvi/es/encyclicals/documents/bf_ben -xvi_20051225_deus-caritas-est.pdf.

${ }_{45}$ Cfr. S. Em. le Cardinal P.-É. LÉGER, Le pauvre Lazare est à notre porte, Paris-Montréal, SOS-Fides, 1967, p. 13. Vid. también el final del discurso de su santidad Pablo VI en el 25. ${ }^{\circ}$ aniversario de la FAO, pronunciado el lunes 16 de noviembre de 1970, disponible en bttps:// w2.vatican.va/content/paul-vi/es/speeches/1970/documents/bf_p-vi_spe_19701116_xxv-isti tuzione-fao.pdf. 
no es ley positiva ${ }^{46}$. En lo concerniente a este punto León XIII había declarado que a nadie se le obliga a socorrer a los demás si para ello ha de privarse uno de lo que precise para su uso personal o de sus deudos. Mas, tan pronto como cubra las necesidades y guarde el lógico decoro, se hace inaplazable que ayude a los indigentes con lo que le sobra [«dad limosna según vuestras facultades», aconseja el Evangelio (Lc. 11, 41) $]^{47}$.

En cuanto a los títulos de dominio, Pío XI alude, amén de a la ocupación de una cosa sin dueño, «también al trabajo o, como suele decirse, la especificación. A nadie se le hace injuria, en efecto, cuando se ocupa una cosa que está al paso y no tiene dueño; y el trabajo, que el hombre pone de su parte y en virtud del cual la cosa recibe una nueva forma o aumenta, es lo único que adjudica esos frutos al que los trabaja» ${ }^{48}$. Repárese, primero, en que la descripción que el papa hace de la ocupación no difiere en demasía de la definición que, entre nosotros, elabora de ella, por ejemplo, Valbuena: «La toma de posesión de una cosa mueble que carece de dueño (corpus) con la voluntad o el ánimo de hacerla propia (animus) ${ }^{49}$. En lo que atiende, en segundo lugar, a ese subtipo de accesión continua (o por incorporación) de mueble a mueble denominada especificación, el esbozo que de la figura nos regala el sumo pontífice no dista mucho del tenor del art. 383.1 CC, para el que consiste en el empleo de «materia ajena en todo o en parte para formar una obra de nueva especie» ${ }^{50}$.

\section{MATER ET MAGISTRA Y PACEM IN TERRIS}

Con ocasión del septuagésimo aniversario de la luminosa y admirable ${ }^{51}$ Rerum Novarum, dictada en una época de profundas transformaciones en

${ }^{46}$ Cfr. Quadragesimo Anno, núm. 47.

${ }^{47}$ Encíclica Rerum Novarum, núm. 17.

${ }^{48}$ Cfr. Quadragesimo Anno, núm. 52.

49 J. A. Valbuena Gutiérrez, en R. Bercovitz Rodríguez-Cano (coord.), Manual de Derecho Civil. Derechos Reales, Madrid, Bercal, 2013, p. 209.

En opinión de L. Díez-Picazo y A. Gullón, Sistema de Derecho Civil, vol. III, t. I, reimp. 8. ${ }^{a}$ ed., Madrid, Tecnos, 2013, p. 170, la ocupación es «un modo de adquirir el dominio de cosas apropiables por naturaleza que no tienen dueño, bien porque nunca lo tuvieron (res nullius), bien porque han sido abandonadas (res derelictae)».

${ }^{50}$ Según R. J. PothieR, Oeuvres de Pothier annotées et mises en corrélation avec le Code Civil et la législation actuelle par M. Bugnet, t. IX, 12. ${ }^{a}$ ed., Paris, Henri Plon-Cosse et Marchal, 1861, p. 162: «On appelle spécification, lorsque quelqu'un a formé et donné l'être à une nouvelle substance, avec une matière qui ne lui appartenait pas».

${ }^{51}$ San Juan XXIII no escatima los elogios a la encíclica Rerum Novarum. La considera 
lo económico y en lo político ${ }^{52}$, el papa San Juan XXIII, como homenaje al escrito leoniano, publicó el día de San Isidro de 1961 la célebre encíclica Mater et Magistra, que sigue desarrollando la cuestión social a la luz de la doctrina de la Iglesia.

El papa Roncalli ${ }^{53}$ reitera, en consonancia con lo anticipado por León XIII y Pío XI, que «el derecho de poseer privadamente bienes, incluidos los de carácter instrumental, lo confiere a cada hombre la naturaleza, y el Estado no es dueño, en modo alguno, de abolirlo» ${ }^{54}$. Y en atención a que la propiedad privada lleva aparejada una «inherente función social» ${ }^{55}$ (lo que repetirá en el núm. 22 de la encíclica Pacem in Terris) ${ }^{56}$, quien disfrute del dominio sobre una cosa debe indefectiblemente ejercitarlo «para beneficio propio y utilidad de los demás» ${ }^{57}$.

Esa función social de la propiedad privada, fórmula acogida, por ejemplo, en el art. 33.2 CE, encarna el último estadio en el lento declive de la visión absolutista del dominio. El retrato de la propiedad como una «función social» se debe al jurista Duguit —quien tomó inspiración de Comte- en los comienzos del siglo xx, y se revela como un recurso transaccional entre la ideología liberal característica de la Revolución Francesa (y los Códigos) y la socialista ${ }^{58}$.

Según el ilustre pensador francés Augusto Comte, «en todo estado normal de la humanidad, cada ciudadano, no importa quién sea, funge de funcionario público, cuyas atribuciones, más o menos definidas, determinan a la vez obligaciones y pretensiones. Este principio universal ha de extenderse ciertamente a la propiedad, en la que el positivismo ve, sobre todo,

una creación «luminosa», «admirable», «trascendental». Cfr. Mater et Magistra, núms. 7, 9 y 41, respectivamente, disponible en bttp:///w2.vatican.va/content/john-xxiii/es/encyclicals/ documents/hf_j-xxiii_enc_15051961_mater.pdf.

52 Se cernía ante los ojos de los asalariados, como una gran amenaza, el espectro del paro, al tiempo que la familia vivía sometida a un proceso paulatino de descomposición. Cfr. Mater et Magistra, núm. 13.

${ }_{53}$ San Juan XXIII (Angelo Giuseppe Roncalli) nació el 25 de noviembre de 1881 en la localidad de Sotto il Monte (a una docena de kilómetros de Bérgamo).

${ }_{54}$ Mater et Magistra, núm. 19.

55 Ibid., núms. 19 y 119.

${ }^{56}$ Que fue publicada el 11 de abril de 1963, disponible en bttp://w2.vatican.va/content/ john-xxiii/es/encyclicals/documents/hf_j-xxiii_enc_11041963_pacem.pdf.

57 Mater et Magistra, núm. 19.

${ }^{58}$ Cfr. C. Lasarte Álvarez, Compendio de derechos reales. Derechos reales e hipotecario, 4. ${ }^{a}$ ed. actualizada con la colaboración de Á. M. MARIÑo DE ANDRÉs y C. NúÑEz MuÑIZ, Madrid, Marcial Pons, 2015, p. 19. Vid. también X. O’Callaghan Muñoz, Compendio de Derecho civil, t. III, Derechos reales e hipotecario, reimp. 5. ${ }^{a}$ ed. corregida y puesta al día, Madrid, Dijusa, 2010, p. 67. 
una indispensable función social encaminada a formar y a administrar los capitales con los cuales cada generación prepara los trabajos de la siguiente. Sabiamente concebida, esta apreciación normal ennoblece su posesión, sin recortar su justa libertad y hasta haciéndola más respetable» ${ }^{59}$.

Con base en tal razonamiento, su compatricio León Duguit manifiesta que «todo individuo tiene la obligación de cumplir en la sociedad una cierta función en razón directa de la posición que en ella ocupa. Ahora bien, el poseedor de la riqueza, por lo mismo que posee la riqueza, puede realizar un trabajo que sólo a él le cabe desempeñar. Sólo él puede aumentar la riqueza general haciendo valer el capital que posee. Está, pues, obligado socialmente a cumplir esta tarea, y no será protegido socialmente más que si la cumple y en la medida en que la cumpla. La propiedad no es, por tanto, el derecho subjetivo del propietario; es la función social del tenedor de la riqueza» ${ }^{60}$.

Retornando a la encíclica Mater et Magistra, el pontífice bergamasco asevera que la justicia social exige que los trabajadores perciban regularmente un salario cuyo importe les permita mantener un «nivel de vida verdaderamente humano y hacer frente con dignidad a sus obligaciones familiares ${ }^{61}$. Además, es deseable que los obreros, en la manera y el grado que parezcan más oportunos, «puedan llegar a participar poco a poco en la propiedad de la empresa donde trabajan» ${ }^{62}$, al intento de que se modere en lo venidero la acumulación de riquezas en manos de los opulentos jefes y éstos repartan las ganancias obtenidas con sus sufridos empleados ${ }^{63}$.

La historia y la experiencia nos enseñan, por otro lado, que en los sistemas políticos que no reconocen a los particulares la propiedad, incluida la de los bienes de producción, «se viola o suprime totalmente el ejercicio de la libertad humana en las cosas más fundamentales, lo cual demuestra con evidencia que el ejercicio de la libertad tiene su garantía y al mismo tiempo su estímulo en el derecho de propiedad» ${ }^{64}$.

El santo padre, repitiendo con sumo agrado las felices observaciones que Pío XII realizó acerca de esta materia (en un radiomensaje de 1 de

59 A. Comte, Système de politique positive ou Traité de sociologie, instituant la religion de l'bumanité, Paris, Librairie Scientifique-Industrielle de L. Mathias, 1851, p. 156 (la cursiva es mía).

${ }^{60}$ L. Duguit, Les transformations genérales du droit privé depuis le Code Napoléon, Paris, Librairie Félix Alcan, 1912, p. 158.

${ }^{61}$ Mater et Magistra, núm. 71.

62 Ibid., núm. 77.

${ }^{63}$ Ibid.

${ }^{64}$ Ibid., núm. 109. 
septiembre de 1944) ${ }^{65}$, explica que «al defender la Iglesia el principio de la propiedad privada persigue un alto fin ético-social. No pretende sostener pura y simplemente el actual estado de cosas, como si viera en él la expresión de la voluntad divina, ni proteger (por norma) al rico y al plutócrata contra el pobre y el indigente. Todo lo contrario, la Iglesia mira sobre todo a lograr que la institución de la propiedad privada sea lo que debe ser, de acuerdo con los designios de la divina Sabiduría y con lo dispuesto por la naturaleza» ${ }^{66}$.

Extraña pues —añade San Juan XXIII - la negación que algunos hacen del antedicho rasgo «natural» del derecho de propiedad, «que halla en la fecundidad del trabajo la fuente perpetua de la eficacia» ${ }^{67}$; es, además, un mecanismo pintiparado para asegurar la dignidad de la persona humana y el desempeño libre de la propia misión en cualquier sector de la actividad económica, y constituye, por último, «un elemento de tranquilidad y de consolidación para la vida familiar, con el consiguiente aumento de paz y prosperidad en el Estado» ${ }^{68}$.

La autoridad del sagrado Evangelio — arguye el «Papa Bueno»— ${ }^{69}$ sanciona, sin duda, el derecho de propiedad privada de los bienes, mas con simultaneidad «presenta con frecuencia a Jesucristo ordenando a los ricos que cambien en bienes espirituales los bienes materiales que poseen y se los den $^{70}$ a los necesitados: "No alleguéis tesoros en la tierra, donde la polilla y el orín los corroen y donde los ladrones horadan y roban. Atesorad tesoros en el cielo, donde ni la polilla ni el orín corroen y donde los

${ }^{65}$ Más precisamente, en el núm. 28 de dicho Radiomensaje, disponible en https://w2.vatican.va/content/pius-xii/es/speeches/1944/documents/bf_p-xii_spe_19440901_al-compiersi.pdf.

${ }_{66}$ Mater et Magistra, núm. 111.

${ }^{67}$ Ibid., núm. 112.

${ }^{68} \mathrm{Ibid}$. Estas mismas palabras las reproduce San Juan XXIII en la encíclica Pacem in Terris, núm. 21.

${ }^{69}$ Todos le llamaban así. Vid., por ejemplo, J. Paredes, «Los papas de la Edad Contemporánea», en VVAA, Diccionario de los papas y Concilios, 3. ${ }^{a}$ ed. actualizada, Barcelona, Ariel, 2005 , p. 547.

Como recoge J.-R. FLECHA ANDRÉs, «Antropología y humanismo de Juan XXIII. Las encíclicas Pacem in Terris y Mater et Magistra», Dialógo Ecuménico, t. XXXVI, núms. 115-116 (2001), p. 325: «Su figura bondadosa llamó poderosamente la atención del mundo entero. Su talante espontáneo delataba una profunda paz interior y un sincero sentimiento religioso. Incluso los no creyentes descubrían en él algo de amable».

${ }^{70}$ Según San Ambrosio de Milán, De Nabutbae, cap. 12, núm. 53: «No le das al pobre de lo tuyo, sino que le devuelves lo suyo. Pues lo que es común y ha sido dado para el uso de todos, lo usurpas tú solo [...] Pagas, pues, un débito, no das gratuitamente lo que no debes» (disponible en http://www.mercaba.org/TESORO/Ambrosio/nabot_el_jezraelita.htm). 
ladrones no horadan ni roban" (Mt. 6, 19-20)» ${ }^{71}$. Sabido es que el Divino Maestro tendrá como hecha o negada a sí mismo la caridad hecha o negada a los menesterosos: «Cuantas veces hicisteis eso a uno de estos mis hermanos menores, a mí me lo hicisteis» (Mt. 25, 40) ${ }^{72}$.

Los derechos naturales —entre ellos el de propiedad — ${ }^{73}$ están estrecha e indisociablemente unidos en el hombre que los ostenta con otros tantos deberes, y aquellos derechos y estos deberes tienen en la ley natural, que los concede o los reclama, «su origen, mantenimiento y vigor indestructible» ${ }^{74}$. En consecuencia, «en la sociedad humana, a un determinado derecho natural de cada hombre correspond[e] en los demás el deber de reconocerlo y respetarlo. Porque cualquier derecho fundamental del hombre deriva su fuerza moral obligatoria de la ley natural, que lo confiere e impone el correlativo deber. Por tanto, quienes, al reivindicar sus derechos, olvidan por completo sus deberes o no les dan la importancia debida, se asemejan a los que derriban con una mano lo que con la otra construyen» ${ }^{75}$.

En vista de que los hombres son criaturas esencialmente sociables, han de convivir entre sí con armonía y perseguir con ahínco y sin descanso cada uno el bien de sus vecinos ${ }^{76}$. Según advertía el apóstol San Pablo: «todos somos miembros unos de otros» (Ef. 4, 25). Por eso, una comunidad humana no será ordenada, fructífera y gozosa sino cuando los ciudadanos, bajo la resplandeciente guía de la justicia, no conculquen los derechos ajenos y cumplan sus propias obligaciones; esto es, obren «movidos por el amor de tal manera que sientan como suyas las necesidades del prójimo y hagan a los demás partícipes de sus bienes, y procuren que en todo el mundo haya un intercambio universal de los valores más excelentes del espíritu humano» ${ }^{77}$.

71 Mater et Magistra, núm. 121.

2 Ibid. Cfr. también epístola I de San Juan 3, 16-17.

73 «Se dice que la propiedad privada es un derecho natural en el sentido de que esta institución se induce, por vía de experiencia, de la naturaleza íntima del hombre considerado en sus aspectos más profundos, tanto en su dimensión personal, con sus disposiciones e impulsos, como en su tendencia y aptitud para perfeccionarse en la vida social mediante el logro de la convivencia humana». Cfr. A. DE FUENMAYOR, «La propiedad privada y su función social», en Estudios de Derecho público y privado ofrecidos al profesor Dr. D. Ignacio Serrano y Serrano, t. I, Valladolid, Publicación de los Seminarios de la Facultad de Derecho con la colaboración del Colegio Mayor Universitario «Menéndez Pelayo» de Valladolid, 1965, p. 227.

74 Pacem in Terris, núm. 28.

75 Ibid., núm. 30.

76 Ibid., núm. 31.

77 Ibid., núm. 35. 
Vidal Rivera Sabatés La propiedad privada y su función social a la luz de cien años...

\section{POPULORUM PROGRESSIO. REFERENCIAS A LA CONSTITUCIÓN PASTORAL GAUDIUM ET SPES Y A LA CARTA APOSTÓLICA OCTOGESIMA ADVENIENS}

Avanzando los años el beato Pablo VI ${ }^{78}$ publicará, el 26 de marzo de 1967, la encíclica Populorum Progressio ${ }^{79}$. Allí, luego de constatar que la cuestión social ha alcanzado una dimensión mundial ${ }^{80}$, se hace eco de una afirmación plasmada en la Constitución pastoral (del Concilio Ecuménico Vaticano II) Gaudium et Spes ${ }^{81}$ : «Dios ha destinado la tierra y todo lo que en ella se contiene para uso de todos los hombres y de todos los pueblos, de modo que los bienes creados deben llegar a todos en forma justa según la regla de la justicia, inseparable de la caridad» ${ }^{82}$. A tenor de ello, nos confiesa el papa Montini ${ }^{83}$, cualquier derecho, hasta el de propiedad privada y comercio libre, está supeditado a tal plan del Señor. Es por eso por lo que la propiedad privada no entraña «para nadie un derecho incondicional y absoluto» ${ }^{84}$, merced a que jamás tiene que ejercitarse «con detrimento de la utilidad común, según la doctrina tradicional de los Padres de la Iglesia y de los grandes teólogos» ${ }^{85}$. No se descubre ninguna razón —apostilla el sucesor de Pedro- para que alguien se reserve «en uso exclusivo lo que supera a la propia necesidad» ${ }^{86}$, cuando a sus semejantes les falta lo mínimo que les garantice la subsistencia.

$\mathrm{El}$ «bien común» requiere en ocasiones la expropiación, que tendrá lugar si «por el hecho de su extensión, de su explotación deficiente o nula, de la miseria que de ello resulta a la población o del daño considerable produci-

78 Pablo VI (Giovanni Battista Enrico Antonio Maria Montini) nació el 26 de septiembre de 1897 en Concesio (pequeño núcleo agrícola a unos ocho kilómetros de Brescia).

${ }^{79}$ Disponible en $b t t p: / / w 2 . v a t i c a n . v a / c o n t e n t / p a u l-v i / e s / e n c y c l i c a l s / d o c u m e n t s / h f \_p$-vi_ enc_26031967_populorum.pdf.

${ }^{80}$ Populorum Progressio, núm. 3. Retomará esta idea en el núm. 5 de la carta apostólica Octogesima Adveniens, de 14 de mayo de 1971, dada por Pablo VI con ocasión del LXXX aniversario de la encíclica Rerum Novarum, disponible en bttp://w2.vatican.va/content/paul-vi/ apost_letters/documents/hf_p-vi_apl_19710514_octogesima-adveniens.pdf.

${ }^{81}$ De 7 de diciembre de 1965, núm. 69, disponible en http://www.vatican.valarchivel bist_councils/ii_vatican_council/documents/vat-ii_const_19651207_gaudium-et-spes_sp.html\#.

${ }_{82}$ Cfr. Populorum Progressio, núm. 22.

83 Ibid.

${ }^{84}$ Ibid., núm. 23. Vid. también las palabras pronunciadas por Juan Pablo I en la Audiencia General del miércoles 27 de septiembre de 1978, disponible en bttp://w2.vatican. va/content/john-paul-i/es/audiences/documents/bf_jp-i_aud_27091978.pdf.

85 Populorum Progressio, núm. 23.

86 Ibid. 
do a los intereses del país, algunas posesiones sirven de obstáculo a la prosperidad colectiva» ${ }^{87}$. En suma, si se aprecia — como establece, por ejemplo, el art. 33.3 CE $-{ }^{88}$ una causa justificada de utilidad pública o interés social ${ }^{89}$.

Al hilo de ello, la mentada Constitución Gaudium et Spes ya había manifestado sin ambages que el derecho de propiedad privada no es incompatible con las diferentes especies de propiedad pública existentes. El tránsito de un bien privativo a la propiedad pública sólo puede ser hecho «por la autoridad competente de acuerdo con las exigencias del bien común y dentro de los límites de este último, supuesta la compensación adecuada» ${ }^{90}$.

Recalca también al respecto la benemérita Constitución que la propiedad privada está empapada de un cariz social, «cuyo fundamento reside en el destino común de los bienes» ${ }^{91}$. Descuidada o postergada dicha índole social, la propiedad se convierte en muchos momentos en nido de ambiciones y germen de graves desórdenes, «hasta el punto de que se da pretexto a sus impugnadores para negar el derecho mismo» ${ }^{92}$.

Abundando en lo anterior, esta clarividente Constitución relata, en un dilatado y enjundioso párrafo, que «en muchas regiones económicamente menos desarrolladas existen posesiones rurales extensas y aun extensísimas mediocremente cultivadas o reservadas sin cultivo para especular con ellas, mientras la mayor parte de la población carece de tierras o posee sólo parcelas irrisorias y el desarrollo de la producción agrícola presenta caracteres de urgencia. No raras veces los braceros o los arrendatarios de alguna parte de esas posesiones reciben un salario o beneficio indigno del hombre, carecen de alojamiento decente y son explotados por los intermediarios. Viven en la más total inseguridad y en tal situación de inferioridad personal que apenas tienen ocasión de actuar libre y responsablemente, de promover su nivel de vida y de participar en la vida social y política. Son, pues, necesarias las reformas que tengan por fin, según los casos, el incremento de las remuneraciones, la mejora de las condiciones laborales, el aumento de la seguridad en el empleo, el estímulo para la iniciativa

${ }^{87}$ Ibid., núm. 24.

${ }^{88}$ Vid. también el art. 349.1 CC o el art. 1.1 LEF, de 16 de diciembre de 1954.

${ }^{89}$ El derecho de propiedad es — según la nítida radiografía hecha por el fundamento jurídico 8. ${ }^{\circ}$ de la STC de 2 de diciembre de 1983 (RTC 1983/111) — un derecho subjetivo «debilitado», «por cuanto cede para convertirse en un equivalente económico cuando el bien de la comunidad [...] legitima la expropiación». Vid. también el fundamento jurídico $2 .^{\circ}$ de la STS de 18 de septiembre de 1998 (RJ 1998/6546).

${ }^{90}$ Gaudium et Spes, núm. 71.

91 Ibid.

${ }^{92}$ Ibid. 
en el trabajo; más todavía, el reparto de las propiedades insuficientemente cultivadas a favor de quienes sean capaces de hacerlas valer. En este caso deben asegurárseles los elementos y servicios indispensables, en particular los medios de educación y las posibilidades que ofrece una justa ordenación de tipo cooperativo. Siempre que el bien común exija una expropiación, debe valorarse la indemnización según equidad, teniendo en cuenta todo el conjunto de las circunstancias» ${ }^{93}$.

\section{LABOREM EXERCENS}

Unos meses después de cumplirse el nonagésimo aniversario de la publicación de la colosal Rerum Novarum (en concreto, el 14 de septiembre de 1981, fiesta de la Exaltación de la Santa Cruz $\left.{ }^{94}\right)$, San Juan Pablo II ${ }^{95}$ dio en Castelgandolfo la encíclica Laborem Exercens $^{96}$. Confirma en ella ${ }^{97}$ el acervo doctrinal de la Iglesia sobre el derecho a la propiedad privada, «incluso cuando se trata de los medios de producción».

Esta concepción del supremo magisterio de la Iglesia se aparta — como pone de resalto el papa polonés- del programa del colectivismo, «proclamado por el marxismo y realizado en diversos países del mundo en los decenios siguientes a la encíclica de León XIII $\gg^{98}$. La citada concepción se distingue igualmente «del programa del capitalismo practicado por el liberalismo» ${ }^{99}$.

La tradición cristiana —enfatiza el beatísimo padre- nunca ha asumido que la propiedad privada fuera «un derecho absoluto e intocable» ${ }^{100}$. Al contrario, ha conectado siempre este dominio «con el derecho común de todos a usar los bienes de la entera creación» ${ }^{101}$; o sea, ha configurado el derecho a la propiedad privada «como subordinado al derecho al uso

93 Ibid.

${ }^{94}$ Según cuenta el mismo santo padre, este documento se había preparado para que fuese publicado el 15 de mayo de 1981, exactamente nueve décadas después de que se diese a conocer la encíclica Rerum Novarum. No obstante, la estancia en el hospital del pontífice retrasó unos meses aquella publicación.

${ }^{95}$ San Juan Pablo II, «el Grande» (de nombre secular Karol Józef Wojtyla), nació en Wadowice (a unos 50 kilómetros de Cracovia) el 18 de mayo de 1920.

${ }_{96}$ Disponible en http://w2.vatican.va/content/john-paul-ii/es/encyclicals/documents/ bf_jp-ii_enc_14091981_laborem-exercens.pdf.

${ }^{77}$ Remitiéndose a la Rerum Novarum. Cfr. Laborem Exercens, núm. 14.

98 Laborem Exercens, núm. 14.

99 Ibid.

${ }^{100}$ Ibid.

${ }^{101}$ Ibid. 
común» ${ }^{102}$, al ya invocado destino universal de las cosas (piedra angular del global armazón ético-social) ${ }^{103}$.

Dicha propiedad privada, por otro lado, no ha de convertirse nunca -nos dice la Iglesia - en un motivo de contraste social en el trabajo. Según refleja el pontífice, «la propiedad se adquiere ante todo mediante el trabajo, para que ella sirva al trabajo» ${ }^{104}$. Y esto se refiere de manera especial al apuntado dominio de los medios de producción: «El considerarlos aisladamente como un conjunto de propiedades separadas con el fin de contraponerlos en la forma del "capital" al "trabajo", y más aún realizar la explotación del trabajo, es contrario a la naturaleza misma de estos medios y de su posesión. Éstos no pueden ser poseídos contra el trabajo, no pueden ser ni siquiera poseídos para poseer, porque el único título legítimo para su posesión - y esto ya sea en la forma de propiedad privada, ya sea en la de propiedad pública o colectiva- es que sirvan al trabajo; consiguientemente que, sirviendo al trabajo, hagan posible la realización del primer principio de aquel orden, que es el destino universal de los bienes y el derecho a su uso común» ${ }^{105}$.

\section{SOLLICITUDO REI SOCIALIS}

El 30 de diciembre de 1987 (décimo año de su fecundo pontificado), San Juan Pablo II publica la encíclica Sollicitudo Rei Socialis ${ }^{106}$, en la que rinde homenaje, por su reciente vigésimo cumpleaños, a la sustanciosa Populorum Progressio de Pablo VI, cuyas enseñanzas, «dirigidas a los hombres y a la sociedad de la década de los sesenta, conservan toda su fuerza de llamado a la conciencia» ${ }^{107}$.

San Juan Pablo II reseña que la encíclica de su «venerado predecesor» ${ }^{108}$ sorprendió a la opinión pública por su novedad ${ }^{109}$, erigiéndose, en cierto modo, como un documento de aplicación de las propuestas del Concilio Vaticano II ${ }^{110}$.

${ }^{102}$ Ibid.

${ }^{103}$ Ibid., núm. 19.

104 Ibid., núm. 14.

${ }^{105}$ Ibid. (la cursiva es del propio texto).

106 Disponible en http://w2.vatican.va/content/john-paul-ii/es/encyclicals/documents/ hf_jp-ii_enc_30121987_sollicitudo-rei-socialis.pdf.

${ }_{107}$ Sollicitudo Rei Socialis, núm. 4 (en cursiva en la encíclica).

108 Sollicitudo Rei Socialis, núm. 2.

${ }^{109}$ Ibid., núm. 5.

${ }^{110}$ Ibid., núm. 6. 
La novedad de que hizo gala esa encíclica pauliana se cifra, según la magnífica exégesis que de ella efectúa el papa de Wadowice, en tres puntos: el primero, componer un texto «emanado de la máxima autoridad de la Iglesia católica y destinado a la vez a la misma Iglesia y "a todos los hombres de buena voluntad" ${ }^{111}$, sobre una materia que prima facie «es sólo económica y social: el desarrollo de los pueblos» ${ }^{112}$. El mérito de la Populorum Progressio, en sintonía con la Rerum Novarum, estriba en señalar el carácter ético y cultural de la problemática relativa al desarrollo, así como en destacar la legitimidad y necesidad de la intervención de la Iglesia en este campo ${ }^{113}$.

El segundo de tales puntos novedosos radica — para un perspicaz San Juan Pablo II- en la «amplitud de horizonte, abierto a lo que comúnmente se conoce bajo el nombre de "cuestión social". En realidad, la encíclica Mater et Magistra del papa Juan XXIII había entrado ya en este horizonte más amplio y el Concilio, en la Constitución pastoral Gaudium et Spes, se había hecho eco de ello. Sin embargo, el magisterio social de la Iglesia no había llegado a afirmar todavía con claridad que la cuestión social ha adquirido una dimensión mundial ${ }^{114}$, ni había llegado a hacer de esta afirmación y de su análisis una "directriz de acción", como hace el papa Pablo VI en su encíclica» ${ }^{115}$.

La tercera novedad de la Populorum Progressio se halla —nos comenta San Juan Pablo II - en la actualización de la mencionada doctrina social de la Iglesia y de la idea misma de desarrollo, pues no en vano al final de aquélla se lee ${ }^{116}$, cual fórmula recapituladora, que «el desarrollo es el nuevo nombre de la paz» ${ }^{117}$.

En relación con ello, el patriarca universal hace hincapié en que el aludido desarrollo «no es un proceso rectilíneo, casi automático y de por sí ilimitado, como si en ciertas ocasiones el género humano marchara seguro hacia una especie de perfección indefinida. Esta concepción — unida a una noción de "progreso" de connotaciones filosóficas de tipo iluminista, más bien que a la de "desarrollo" usada en sentido específicamente económicosocial- parece puesta ahora seriamente en duda, sobre todo después de la

${ }^{111}$ Ibid., núm. 8.

112 Ibid. (la cursiva es del documento).

113 Ibid.

114 Vid. nota 80.

115 Sollicitudo Rei Socialis, núm. 9 (la cursiva es del original).

116 Populorum Progressio, núm. 87.

117 Sollicitudo Rei Socialis, núm. 10. 
trágica experiencia de las dos guerras mundiales, de la destrucción planeada y en parte realizada de poblaciones enteras, y del peligro atómico que amenaza. A un ingenuo optimismo mecanicista le reemplaza una fundada inquietud por el destino de la humanidad» ${ }^{118}$.

También sufre una crisis de gran calado la propia concepción «económica» o «economicista» vinculada al vocablo desarrollo. En efecto - advierte el Santo Padre-, hogaño se comprende mejor que «la mera acumulación de bienes y servicios, incluso en favor de una mayoría, no basta para proporcionar la felicidad humana. $\mathrm{Ni}$, por consiguiente, la disponibilidad de múltiples beneficios reales, aportados en los tiempos recientes por la ciencia y la técnica, incluida la informática, traen consigo la liberación de cualquier forma de esclavitud» ${ }^{119}$. Si tal ingente masa de recursos y potencialidades, colocados en manos del hombre, no es regida por un objetivo moral (que los oriente hacia la consecución del bien de la humanidad), esa masa se vuelve sin dificultad contra dicho hombre para oprimirlo o subyugarlo ${ }^{120}$.

Se comprueba igualmente con desconcierto en los últimos años - reflexiona con indisimulada pesadumbre su santidad-que, junto a las intolerables miserias del subdesarrollo, despunta una suerte de «superdesarrollo» inaceptable, por ser enemigo del bien y la felicidad auténtica ${ }^{121}$. Este «superdesarrollo», que se traduce en «la excesiva disponibilidad de toda clase de bienes materiales para algunas categorías sociales, fácilmente hace a los hombres esclavos de la "posesión" y del goce inmediato, sin otro horizonte que la multiplicación o la continua sustitución de los objetos que se poseen por otros todavía más perfectos. Es la llamada civilización del "consumo" o consumismo, que comporta tantos "desechos" o "basuras". Un objeto poseído y ya superado por otro más perfecto es descartado simplemente, sin tener en cuenta su posible valor permanente para uno mismo o para otro ser humano más pobre» ${ }^{122}$.

Es menester, por ello, que el hombre acate a pie juntillas la voluntad del Señor, que le dibuja «límites en el uso y dominio de las cosas (Gén. 2, 16 y s.), a la par que le promete la inmortalidad (Gén. 2, 9; Sab. 2, 23)» ${ }^{123}$. De resultas de esta bíblica enseñanza, el desarrollo no puede sólo con-

\footnotetext{
118 Ibid., núm. 27 (la cursiva está en el original).

119 Ibid., núm. 28.

120 Ibid.

121 Ibid.

122 Ibid.

123 Ibid., núm. 29.
} 
sistir «en el uso, dominio y posesión indiscriminada de las cosas creadas y de los productos de la industria humana, sino más bien en subordinar la posesión, el dominio y el uso a la semejanza divina del hombre y a su vocación a la inmortalidad. Ésta es la realidad trascendente del ser humano, la cual desde el principio aparece participada por una pareja, hombre y mujer (Gén. 1, 27), y es, por consiguiente, fundamentalmente social» ${ }^{124}$.

Trae a la memoria, asimismo, el santo padre, una vez más ${ }^{125}$, el peculiar mandamiento de la doctrina cristiana, que proclama a voz en grito que «los bienes de este mundo están originariamente destinados a todos» ${ }^{126}$. El derecho a la propiedad privada es «válido y necesario» ${ }^{127}$, mas la admisión del dominio particular no anula la vigencia y entidad de dicho mandamiento. Cualquier propiedad privada está gravada con una «hipoteca social» ${ }^{128}$ (sintagma acuñado por el mismo San Juan Pablo II en su discurso de inauguración de la III Conferencia General del Episcopado Latinoamericano, pronunciado en la ciudad mexicana de Puebla el 28 de enero de 1979 ${ }^{129}$ ); es decir, tal propiedad exhibe, como cualidad intrínseca, una función social cimentada en la inmarcesible búsqueda del «destino universal de los bienes» ${ }^{130}$.

\section{CENTESIMUS ANNUS}

El 1 de mayo de 1991 (festividad de San José Obrero), San Juan Pablo II, impelido por el deseo de celebrar el centenario de la promulgación de la Rerum Novarum, firma la encíclica Centesimus Annus. En ella propone una

${ }^{124}$ Ibid. (la cursiva es del original).

125 Cfr. Laborem Exercens, núms. 14 y 19.

126 Sollicitudo Rei Socialis, núm. 42.

${ }^{127}$ Ibid.

${ }^{128}$ Ibid.

129 III, 4, disponible en bttp://w2.vatican.valcontent/john-paul-ii/es/speeches/1979/ january/documents/hf_jp-ii_spe_19790128_messico-puebla-episc-latam.pdf.

San Juan Pablo II vuelve a emplear el sintagma «hipoteca social» al día siguiente (29 de enero de 1979) en su discurso a los indígenas y campesinos de México pronunciado en Culiapán, disponible en https://w2.vatican.va/content/john-paul-ii/es/speeches/1979/ january/documents/hf_jp-ii_spe_19790129_messico-culiapan-indios.pdf.

130 Sollicitudo Rei Socialis, núm. 42. En la homilía que su santidad Juan Pablo II pronunció durante la misa celebrada para los agricultores en Recife (Brasil) el 7 de julio de 1980 explicó que «en el uso de los bienes poseídos, el destino general que Dios les dio y las exigencias del bien común han de prevalecer sobre las ventajas, comodidades $\mathrm{y}$, a veces, incluso necesidades no primarias de origen privado» (disponible en https://w2.vatican.va/content) john-paul-ii/es/bomilies/1980/documents/hf_jp-ii_hom_19800707_recife-brazil.pdf). 
«relectura» ${ }^{131}$ del texto leoniano, «echando una mirada retrospectiva» ${ }^{132}$ para descubrir de nuevo su perspicua letra. Interesa mostrar cómo la «rica savia» ${ }^{133}$ que sube de su raíz no se ha agotado con el transcurso de los años, sino que, por el contrario, se ha tornado más nutritiva.

San Juan Pablo II afronta, pues, a punto de arribar al tercer milenio de la era cristiana (un futuro cargado de incógnitas y desafíos), una ilusionada puesta al día de los postulados tradicionales de la Iglesia, que tienen un valor perenne ${ }^{134}$. Se inspira para ello en la imagen evangélica del «escriba que se ha hecho discípulo del Reino de los cielos» ${ }^{135}$, del cual dice el Señor que «es como el amo de casa que saca de su tesoro cosas nuevas y cosas viejas (Mt. 13, 52)» ${ }^{136}$. Este tesoro —nos ilustra el santo padre- lo constituye la gran corriente doctrinal de la Iglesia, que alberga las «cosas viejas», recibidas y transmitidas desde siempre, y que permite encontrar las «cosas nuevas», en medio de las cuales camina nuestra existencia ${ }^{137}$.

León XIII se hallaba, al elaborar la Rerum Novarum, ante una sociedad dividida por un enfrentamiento, «tanto más duro e inhumano en cuanto no conocía reglas ni normas» ${ }^{138}$. Se trataba del conflicto entre el capital y el trabajo, o, en palabras de la encíclica leoniana, de la «cuestión obrera». Era — resume San Juan Pablo II- un conflicto que contraponía, al estilo del comediógrafo Plauto ${ }^{139}$, como si fueran «lobos», un hombre a los demás, «incluso en el plano de la subsistencia física de unos y la opulencia de otros» ${ }^{140}$, por lo que el papa italiano sintió el deber de intervenir en razón de su oficio apostólico ${ }^{141}$, esto es, de la tarea encomenda-

${ }^{131}$ Centesimus Annus, núm. 3, disponible en bttp://w2.vatican.va/content/john-paul-iil es/encyclicals/documents/bf_jp-ii_enc_01051991_centesimus-annus.pdf.

132 Ibid.

133 Ibid., núm. 1.

${ }_{134}$ Ibid., núm. 3. Vid. al respecto, también, J. Fernández AguAdo, «En el centenario de la Rerum Novarum», Cuadernos de Estudios Empresariales, núm. 1 (1991), p. 54.

135 Centesimus Annus, núm. 3.

136 Ibid.

137 Ibid. Cfr. también el núm. 15 de la carta encíclica Laudato si' del santo padre Francisco, publicada el 24 de mayo de 2015, disponible en http://w2.vatican.va/content/francesco/es/encyclicals/documents/papa-francesco_20150524_enciclica-laudato-si.pdf).

${ }_{138}$ Centesimus Annus, núm. 5.

139 «Cuando una persona te es desconocida [...] es para ti como un lobo, no un hombre», manifestará desengañado este autor en la Comedia de los Asnos (acto II, escena cuarta). Cfr. T. M. Plauto, Comedias, t. I, Anfitrión-La Comedia de los Asnos-La Comedia de la Olla-Las dos Báquides-Los cautivos-Cásina, introducción, traducción y notas de M. GonZÁLEZ-HaBA, Madrid, Gredos, 1992, p. 138.

${ }^{140}$ Centesimus Annus, núm. 5.

${ }^{141}$ Cfr. Rerum Novarum, núm. 1. 
da por Jesucristo de «apacentar los corderos y las ovejas» (Jn. 21, 15-17) y de «atar y desatar» en la tierra por el Reino de los cielos (Mt. 16, 19) ${ }^{142}$. Anhelaba León XIII restablecer la paz, y era consciente de que esa paz se había de edificar sobre el pilar de la justicia ${ }^{143}$ y la defensa de la dignidad del trabajador ${ }^{144}$.

San Juan Pablo II cree que el mundo moderno demanda sin demora una «nueva evangelización» ${ }^{145}$, y ella debe incluir como elemento medular el anuncio de la doctrina social de la Iglesia ${ }^{146}$, que, como en la época de León XIII, sigue siendo idónea para indicar la recta senda a la hora de responder a los grandes retos contemporáneos, mientras crece el descrédito de las ideologías ${ }^{147}$. No cabe, por ende, verdadera solución para la «cuestión social» fuera del Evangelio ${ }^{148}$. Hay que apoyarse, antes de nada, en la correcta visión de la persona humana y de su carácter singular ${ }^{149}$, porque el hombre es «la única criatura terrestre a la que Dios ha amado por sí misma» ${ }^{150}$. Lo ha modelado a su imagen y semejanza (Gn. 1, 26), confiriéndole una excelencia incomparable. Así, al margen de los derechos que el hombre adquiere con su propio trabajo, tiene también otros derechos que no derivan de ninguna obra acometida por él, sino que dimanan de su dignidad esencial de persona ${ }^{151}$.

En conexión con lo expuesto, el pontífice eslavo aboga por una «sana concepción de la propiedad privada» ${ }^{152}$, que es un derecho natu$\mathrm{ral}^{153}$ del ser humano, «fundamental en toda persona para su autonomía y desarrollo» ${ }^{154}$. La Iglesia predica, sin embargo, que el dominio de las cosas, lícito per se, no es un derecho absoluto, ya que en sus entrañas lleva inscrita la propia limitación ${ }^{155}$. Tiene el dominio, por tanto, una faceta o

142 Centesimus Annus, núm. 5.

143 Ibid.

144 Ibid., núm. 6.

145 Benedicto XVI lo expresa con sencillez: «El hombre necesita a Dios, de lo contrario queda sin esperanza». Cfr. el núm. 23 de su carta encíclica Spe Salvi, de 30 de noviembre de 2007, disponible en http://w2.vatican.va/content/benedict-xviles/encyclicals/documents/bf_ ben-xvi_enc_20071130_spe-salvi.pdf.

146 Centesimus Annus, núms. 5 y 54.

147 Cfr. Centesimus Annus, núm. 5.

148 Ibid.

149 Ibid., núm. 11.

150 Cfr. Gaudium et Spes, núm. 24.

151 Centesimus Annus, núm. 11.

152 Ibid.

153 Ibid., núm. 30.

154 Ibid.

155 Ibid. 
proyección social, identificada con la inveterada tesis del «destino común de los bienes» ${ }^{156}$.

Se puede indagar entonces - plantea el servus servorum Dei- cuál es la procedencia de los bienes que sustentan la vida del hombre, que satisfacen sus necesidades y son objeto de sus derechos ${ }^{157}$. A propósito de este asunto, convengamos que «el origen primigenio de todo lo que es un bien es el acto mismo de Dios que ha creado el mundo y el hombre, y que ha dado a éste la tierra para que la domine con su trabajo y goce de sus frutos (Gn. 1, 28-29)» ${ }^{158}$. El Señor ha regalado la tierra a todo el género humano para que ella mantenga a todos sus habitantes, «sin excluir a nadie ni privilegiar a ninguno. He ahí la raíz primera del destino universal de los bienes de la tierra» ${ }^{159}$. No obstante, la tierra solo brinda sus copiosos frutos a cambio de la esforzada actuación del hombre, reflejada en su diario quehacer. Mediante su trabajo, la persona, usando su ingenio y su libertad, logra dominarla y transformarla en su digna morada. De esta manera, se apropia de una parte de la tierra, la que ha conquistado con su trabajo: ése es «el origen de la propiedad individual» ${ }^{160}$. Obviamente — concluirá el vicario de Jesucristo- le incumbe también la responsabilidad de no impedir que otros hombres obtengan su parte del don divino; «es más, debe cooperar con ellos para dominar juntos toda la tierra» ${ }^{161}$.

En los inicios de cualquier sociedad humana a lo largo de la historia, nos topamos siempre con esos dos factores señalados (el trabajo y la tierra), pero la relación entre ellos va mutando en el curso de los años. En otros tiempos, la natural fecundidad de la tierra suponía el principal instrumento de riqueza, mientras que el trabajo servía de ayuda y favorecía tal fecundidad ${ }^{162}$. En nuestra época, por el contrario, es - certifica el pontífice- cada vez más decisivo el rol del trabajo humano «en cuanto factor productivo de las riquezas inmateriales y materiales» ${ }^{163}$. Resulta, asimismo, evidente que el trabajo de un hombre se liga naturalmente con el de otros hombres. Más que en el pasado, en la actualidad trabajar es «trabajar con otros y trabajar para otros: es hacer algo para alguien» ${ }^{164}$.

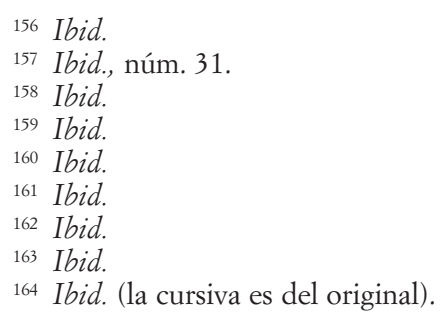


El trabajo es tanto más provechoso y rentable «cuanto el hombre se hace más capaz de conocer las potencialidades productivas de la tierra y ver en profundidad las necesidades de los otros hombres, para quienes se trabaja» ${ }^{165}$.

Emerge, por lo demás, otro tipo de propiedad —observa San Juan Pablo II—, de gran relieve en el presente, que tiene «una importancia no inferior a la de la tierra: la propiedad del conocimiento, de la técnica y del saber ${ }^{166}$. En dicha clase de propiedad, mucho más que en los recursos naturales, reposa hoy la riqueza de las naciones industrializadas ${ }^{167}$.

Le desazona al papa, por último, que el hombre, bajo los ciegos impulsos de una irrefrenable ansia de tener y gozar, más que de ser y de crecer, consume con ritmo raudo y desordenado los recursos del planeta y su misma vida ${ }^{168}$. Tales recursos naturales no son ilimitados, por lo que usarlos «como si fueran inagotables, con dominio absoluto, pone seriamente en peligro su futura disponibilidad» ${ }^{169}$ no sólo para nuestra generación, sino sobre todo para las venideras.

Se atisba como causa de la imprudente devastación del medio natural «un error antropológico» ${ }^{170}$, por desgracia muy extendido ahora. El individuo, que descubre alborozado «su capacidad de transformar y, en cierto sentido, de "crear" el mundo con su propio trabajo, olvida que éste se desarrolla siempre sobre la base de la primera y originaria donación de las cosas por parte de Dios» ${ }^{171}$. Ayuno de sensatez, el ser humano piensa que le cabe disponer arbitrariamente de la tierra, aherrojándola sin reservas a su caprichosa voluntad cual si ella no tuviese «una fisonomía propia y un destino anterior dados por Dios, y que el hombre puede desarrollar ciertamente, pero que no debe traicionar» ${ }^{172}$. En lugar de afanarse en desempeñar su papel de colaborador del Todopoderoso en la obra de la creación, el hombre suplanta a Dios y desencadena con ello la rebelión de la naturaleza, que se siente tiranizada por la desaforada voracidad de los mortales ${ }^{173}$ (expresión de lo que el papa Francisco denominará un «antropocentris-

\footnotetext{
165 Ibid.

166 Ibid., núm. 32 (la cursiva es del original).

${ }^{167}$ Ibid.

168 Ibid., núm. 37.

169 Sollicitudo Rei Socialis, núm. 34 (la cursiva aparece en el original).

170 Centesimus Annus, núm. 37.

${ }_{171}$ Ibid.

172 Ibid.

${ }^{173}$ Ibid. Cfr. también Sollicitudo Rei Socialis, núm. 34.
} 
Vidal Rivera Sabatés La propiedad privada y su función social a la luz de cien años...

mo despótico») ${ }^{174}$. Pretendía el Creador — sintetiza San Juan Pablo IIque el hombre se pusiera en contacto con dicha naturaleza como «dueño» y «custodio» inteligente y noble, y no como «explotador»y «destructor» sin ningún reparo ${ }^{175}$.

174 Cfr. encíclica Laudato si', núm. 68.

175 Cfr. el núm. 15 de la encíclica Redemptor Hominis, publicada el 4 de marzo de 1979, disponible en http://w2.vatican.va/content/john-paul-iiles/encyclicals/documents/hf_jp-ii_ enc_04031979_redemptor-hominis.pdf.

Foro, Nueva época, vol. 19, núm. 2 (2016): 275-297 
